Instructions for authors, subscriptions and further details:

http://ijep.hipatiapress.com

\title{
Rethinking Early Literacies. Reading and Rewriting Worlds
}

Andrea Khalfaoui Larrañaga ${ }^{1}$

1) University of Deusto, Spain

Date of publication: June $24^{\text {th }}, 2018$

Edition period: June 2018 - October 2018

To cite this review: Khalfaoui, A. (2018). [Review of the book Rethinking Early Literacies. Reading and rewriting worlds by Souto-Manning, M., and Yoon, H.S] International Journal of Educational Psychology, 7(2), 227-229. doi:10.17583/ijep.2018.3531

To link this review: http://dx.doi.org/10.17583/ijep.2018.3531

\section{PLEASE SCROLL DOWN FOR ARTICLE}

The terms and conditions of use are related to the Open Journal System and to Creative Commons Attribution License (CC-BY).

2018 Hipatia Press

ISSN: 2014-3591

DOI: $10.17583 /$ ijep.2018.3531

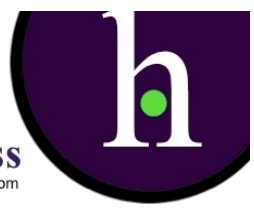


IJEP - International Journal of Educational Psychology, Vol. 7 No. 2 June 2018 pp. 227-229

\section{Review}

Souto-Manning, M., Yoon, H.S (2018). Rethinking Early Literacies. Reading and rewriting worlds. Routledge

Reflection is key in the learning process. As Jerome Bruner (1996) contends, reflection is the action that makes it possible for us to go beyond the confines of our knowledge. Every educational professional should be aware of the importance of reflection in key issues such as literacy, as it continues to be one of the most important elements of academic success. Based on this premise, Rethinking Early Literacies tackles the meaning and understanding of early literacies. Similarly, it invites us to rethink children's literate identities, paying attention to power and social justice.

By adopting a critical perspective, this book calls for a reconceptualisation of what literacies are and what must be done to achieve success for all. The authors proceeded with this task by reframing what it means to be literate in this contemporary and diverse society. They pay special attention to discuss the role of educators in theorizing and rethinking language ideologies for practice. To this end, many examples taken from real school situations are given.

The book invites the readers to think and reflect beyond conventionalisms about early literacies. As the ways we interpret concepts and ascribe meanings in our everyday practice as educators have significant implications in children's learning processes and outcomes, more critical approaches are needed to better understand its nuances and complexities. The book highlights diversity as a positive and relevant feature of our society, calling for collective support to sustain historically minoritized communities such as people of colour.

Rethinking early literacies gathers an interesting array of school experiences, making a relevant contribution to overcoming academic and social 
228 Khalfaoui - Rethinking Early Literacies. Reading and rewriting worlds [Book Review]

inequalities that result from a partial and incomplete perspective of what it means to be literate. Many children around the world are being labeled as "not good enough" in their literacy classes. While this common practice has a strong negative effect on subsequent academic stages, this negative label often stems from a limited understanding of literacies. Indeed, there is value in its other forms such as home literacies, community literacies and those that children create between peers. The book puts these valuable literacy spaces to the fore and argues for their important roles in learning development.

The structure of the book divides the content into three thematic parts, carefully woven together through arguments and examples from preschool classrooms. In what follows, the main contribution of each chapter is briefly exposed, tackling pertinent issues such as racism, immigration rights and readiness.

The first part invites us to rethink our conceptions about children's positioning in literacy. This first chapter explores the key concepts of identity, culture and agency in understanding what it means to be literate. Through real examples mixed with consolidated theories, Souto-Manning and Yoon emphasize that children are more than passive literacy consumers: they are producers and active agents.

The second part, Spaces of belonging: relational literacies, focuses on the multiple contexts in which children take active part. The main idea here is that children's cultural spaces are multiple and all of them are valuable. From family context to community spaces, this second chapter include those contexts as important considerations in the learning process, making them just as valuable as the school setting. Peer cultures are also included in this chapter, wherein children create their own set of language and literacy repertoires as a way to engage with their peers. This shared set of literacy practices come through shared knowledge and understanding, that is only possible through interactions.

In part three, rethinking early literacies: children's literate identities in contemporary times, the authors discuss the complexity of children's literate identities and challenge socially constructed literacies based on gender, race, socioeconomic status and linguistic varieties. Through this perspective, the 
authors examine the curriculum, classroom interactions and research with the aim of creating productive spaces for children to practice multiple literacies.

Overall, the authors theorize the literacy of young children in a way that invites early childhood educators and researchers to rethink theoretical constructs framing understandings of literacy in contemporary societies. This perspective includes adopting a critical perspective on artefacts related to childhood such as movies, toys, and drawings to expand and reconstruct the underlying assumptions and meanings inscribed in and reproduced by popular culture. The book's takeaway message is clear: ultimately, concepts must be responsive to reality in order to contribute to overcoming inequalities. As identities are narrative constructions that are in the process of continuous change, this book invites us to take active part in our own practices and theoretizations. As nothing is fixed nor stable, the challenge is to continuously engage in reflective practice and thoughtful interactions in order to contribute to genuinely inclusive literacy, even in early childhood.

\section{References}

Bruner, J. (1996) The Culture of Education. Harvard University Press

Andrea Khalfaoui Larrañaga University of Deusto andrea.khalfaoui@deusto.es 